\title{
Differential site accessibility mechanistically explains subcellular-specific $N$-glycosylation determinants
}

\section{Ling Yen Lee, Chi-Hung Lin, Susan Fanayan, Nicolle H. Packer and Morten Thaysen-Andersen*}

Department of Chemistry and Biomolecular Sciences, Biomolecular Frontiers Research Centre, Macquarie University, Sydney, NSW, Australia

\section{Edited by:}

Elizabeth Yuriev, Monash University, Australia

\section{Reviewed by:}

Jamie Heimburg-Molinaro, Emory

University, USA

Tony Velkov, Monash University,

Australia

\section{*Correspondence:}

Morten Thaysen-Andersen,

Department of Chemistry and

Biomolecular Sciences, Biomolecular

Frontiers Research Centre, Macquarie

University, Sydney, NSW 2109,

Australia

e-mail:morten.andersen@mq.edu.au
Glycoproteins perform extra- and intracellular functions in innate and adaptive immunity by lectin-based interactions to exposed glyco-determinants. Herein, we document and mechanistically explain the formation of subcellular-specific $\mathrm{N}$-glycosylation determinants on glycoproteins trafficking through the shared biosynthetic machinery of human cells. LC-MS/MS-based quantitative glycomics showed that the secreted glycoproteins of eight human breast epithelial cells displaying diverse geno- and phenotypes consistently displayed more processed, primarily complex type, $\mathrm{N}$-glycans than the highmannose-rich microsomal glycoproteins. Detailed subcellular glycome profiling of proteins derived from three breast cell lines (MCF7/MDA468/MCF10A) demonstrated that secreted glycoproteins displayed significantly more $\alpha$-sialylation and $\alpha 1$,6-fucosylation, but less $\alpha$-mannosylation, than both the intermediately glycan-processed cell-surface glycoproteomes and the under-processed microsomal glycoproteomes. Subcellular proteomics and gene ontology revealed substantial presence of endoplasmic reticulum resident glycoproteins in the microsomes and confirmed significant enrichment of secreted and cell-surface glycoproteins in the respective subcellular fractions. The solvent accessibility of the glycosylation sites on maturely folded proteins of the 100 most abundant putative $N$-glycoproteins observed uniquely in the three subcellular glycoproteomes correlated with the glycan type processing thereby mechanistically explaining the formation of subcellular-specific $N$ glycosylation. In conclusion, human cells have developed mechanisms to simultaneously and reproducibly generate subcellular-specific $N$-glycosylation using a shared biosynthetic machinery. This aspect of protein-specific glycosylation is important for structural and functional glycobiology and discussed here in the context of the spatio-temporal interaction of glyco-determinants with lectins central to infection and immunity.

Keywords: $\boldsymbol{N}$-glycosylation, solvent accessibility, $\boldsymbol{N}$-glycome, subcellular location, glycoproteome, glycosylation site, $N$-glycan, glycoprotein

\section{INTRODUCTION}

Significant parts of the human genome and cellular energy are dedicated to produce and regulate protein glycosylation (1). Hence, it is no surprise that this abundant post-translational modification is important in a wide spectrum of biological processes to maintain cellular homeostasis (2). Dysregulation of protein glycosylation is a cause and/or effect of numerous pathological conditions including, but not limited to, congenital disorder of glycosylation (3), cystic fibrosis (4), inflammation (5), auto-immunity (6), and cancer (7). The extracellular location of secreted and cell-surfacetethered proteins carrying $N$-linked glycosylation is ideal for facilitating molecular interactions with the surrounding environment (8). Intracellular functions of $\mathrm{N}$-glycoproteins are also known $(9,10)$. The terminal determinants of host $N$-glycans (so-called "self" and "altered self" in disease) are recognized by endogenous and exogenous glycan-binding proteins commonly called lectins. Interactions between lectins and $N$-glycans are central in innate and adaptive immunity (11). Important examples include the Ctype lectins, which may be crudely divided into lectins having affinity for $\alpha$-mannose $/ \alpha$-fucose-terminated $N$-glycans including dendritic cell-specific intercellular adhesion molecule-3-grabbing non-integrin (DC-SIGN), macrophage mannose receptors and Langerin (12), and lectins having affinity for galactose/GalNAc terminating glycans such as macrophage galactose lectin and DCasialoglycoprotein receptor $(13,14)$. In addition, siglecs (I-type lectins) and galectins (S-type lectins) are important for facilitating a functional immune response (15).

The human $\mathrm{N}$-glycosylation biosynthetic machinery is relatively well understood $(16,17)$. In brief, the synthesis is initiated by the transfer of common immature glycan precursors i.e., $\mathrm{Glc}_{3} \mathrm{Man}_{9} \mathrm{GlcNAc}_{2}$ to conserved sequons $(\mathrm{NxT} / \mathrm{S}, \mathrm{x} \neq \mathrm{P}$ ) on translocating polypeptide chains. The glycan precursor is then remodeled through sequential trimming and elongation by specific glycosidases and glycosyltransferases located in the endoplasmic reticulum (ER) and the cis-, medial, and trans-Golgi, respectively. This series of enzymatic processes first results in the trafficking $N$-glycoproteins being comprised of attached high-mannosetype $\mathrm{N}$-glycans, which progresses to the hybrid- and complex-type stage if sufficient interactions with the processing enzymes occur (17). The Golgi-based N-glycan processing, including the formation of glycan types and the addition of terminal determinants such as $\alpha$-fucosylation and $\alpha$-sialylation, occurs on maturely folded 
glycoproteins $(18,19)$. An extensive and reproducible repertoire of $N$-glycans is usually present on a given glycosylation site (20). This $N$-glycan microheterogeneity on proteins results from incomplete processing by the multiple competing enzymatic reactions that can be influenced by cellular factors including the availability of nucleotide sugars, glycosylation enzyme activity, and glycoprotein trafficking time through the biosynthetic machinery. Such cellular factors contribute to cell- and tissue-specific $N$-glycosylation (21). Importantly, the structures of the individual glycoproteins trafficking through the glycosylation machinery dramatically influence the degree of $N$-glycan processing creating protein- and site-specific $N$-glycosylation (22). By thorough literature-based curation of published site-specific glycoprofiling data of mammalian $N$-glycoproteins, we recently confirmed that several structural features including glycan type formation, $\alpha 1,6$ (core) fucosylation, and $\beta 1,4 / 6$-GlcNAc branching of $N$-glycans are strongly correlated with the solvent accessibility of the glycosylation sites of maturely folded glycoproteins (19). As such, extensive $N$-glycan processing was observed for proteins displaying solvent accessible glycosylation sites relative to spatially hidden sites. Thus, differential site accessibility can explain how glycoproteins produced simultaneously in the same cell, and even sequons on the same glycoproteins, can present widely different $N$-glycan structural repertoires.

Considering the importance of protein- and site-specific $N$ glycosylation in many aspects of glycobiology including glycoimmunology, we here seek to further explore this feature in the context of the multiple subcellular glycoproteomes that traffic through the shared glycosylation machinery in the secretory pathway of human cells, yet end up at different cellular locations. Due to the functional implications of both intra- and extracellular $N$-glycoproteins, we focus on the secreted, cell-surface, and intracellular glycoproteomes, the latter fraction largely represented by microsomal proteins (23). Understanding, how the subcellular glycoproteomes are generated and regulated under normal and altered physiological conditions of the cell is valuable to the understanding of their involvement in immune biology. Recent analytical developments in glycomics (24-27) and glycoproteomics (28-31) have, together with more conventional proteomics, enabled sensitive, and detailed system-wide investigations of the regulation of protein $\mathrm{N}$-glycosylation in immunity (32).

Using LC-MS/MS-based glycomics and proteomics on multiple subcellular fractions from a panel of human cell lines displaying diverse cellular characteristics, we here document that human cells have developed a general mechanism to reproducibly generate vastly different $N$-glycan determinants on their differently located subcellular glycoproteomes that trafficked simultaneously through a shared biosynthetic machinery. We provide evidence that the subcellular-specific protein $N$-glycosylation arises from differential solvent accessibilities of the glycosylation sites of maturely folded glycoproteins that localize to different subcellular compartments following the glycan processing. This aspect of protein-specific glycosylation is discussed here in the context of immunity and infection due to the crucial role of endogenous and exogeneous lectins recognizing exposed self, and altered self, glyco-determinants to facilitate the functional immune response.

\section{MATERIALS AND METHODS CELLULAR ORIGIN, CULTURE CONDITIONS, AND DOUBLING TIME}

Multiple human cells showing diverse geno- and phenotypical characteristics were used to demonstrate the general nature of the cellular mechanisms observed in this study. Human mammary epithelial cells (HMEC) were purchased (product \# CC2551, Lonza). Human breast epithelial cell lines MCF10A, MCF7, SKBR3, MDA-MB-157 (MDA157), MDA-MB-231 (MDA231), and HS578T as well as a human colon cancer epithelial cell line SW480 were obtained from American Type Culture Collection (Manassas, VA, USA). HMEC was grown in HuMEC Ready Media (Invitrogen). MCF10A was cultured in DMEM/F12 with the addition of $5 \%$ horse serum (Invitrogen), $20 \mathrm{ng} / \mathrm{mL}$ epidermal growth factor (EGF) (Invitrogen), $0.5 \mu \mathrm{g} / \mathrm{mL}$ hydrocortisone (Sigma), $100 \mathrm{ng} / \mathrm{mL}$ cholera toxin (Sigma), and $8 \mu \mathrm{g} / \mathrm{mL}$ insulin (Invitrogen). Other cell lines were grown in RPMI (Sigma) supplemented in 5\% fetal bovine serum (FBS) (Invitrogen), $10 \mathrm{mM}$ glutamine (Invitrogen), and $10 \mu \mathrm{g} / \mathrm{mL}$ insulin. Cells were maintained at $37^{\circ} \mathrm{C}$ in $5 \% \mathrm{CO}_{2}$ for all experiments. The breast cell lines were grown in triplicates to $\sim 80 \%$ confluence and washed at least four times with ice-cold phosphate buffered saline (PBS) to remove traces of FBS and incubated in serum-free media at $37^{\circ} \mathrm{C}$ in $5 \% \mathrm{CO}_{2}$ for $48 \mathrm{~h}$ prior to subcellular fractionation.

To measure the cellular doubling times of the breast cell lines, cells were seeded at $1.3 \times 10^{4}$ cells/mL/well in six-well plates and incubated overnight at $37^{\circ} \mathrm{C}$ in $5 \% \mathrm{CO}_{2}$. Cells were counted every $24 \mathrm{~h}$ over a four-day period using a cell counter (Bio-Rad). The doubling time for each cell line was determined from their exponential growth phase. For overview of the investigated cells and associated data, see Table S1 in Supplementary Material.

\section{COLLECTION AND PREPARATION OF SUBCELLULAR GLYCOPROTEOMES FROM BREAST CELL LINES}

The secreted subcellular glycoproteomes were collected by sampling $30 \mathrm{~mL}$ of serum-free culture media followed by centrifugation at 2,000 $\times g$ to pellet any floating cells. The supernatants were concentrated and buffer exchanged into PBS $(1 \times)$ using 10,000 MWCO Amicon Ultra membranes (Millipore). Proteins were then precipitated with nine volumes of acetone overnight at $-20^{\circ} \mathrm{C}$. The pellets were stored at $-80^{\circ} \mathrm{C}$ until further analysis.

The cell-surface subcellular glycoproteomes were isolated from MCF7, MDA468, and MCF10A breast epithelial cell lines using a commercial biotinylation kit (product \# 89881, Pierce) to specifically biotinylate the cell-surface glycoproteins. The protocol supplied by the manufacturer was followed. Briefly, monolayers of cultured cells grown in $75 \mathrm{~cm}^{2}$ culture flasks were washed threetimes with PBS $(1 \times)$ before incubation in EZ-Link sulfo-NHSSS-biotin in ice-cold PBS $(1 \times)$ for $30 \mathrm{~min}$ at $4^{\circ} \mathrm{C}$ on a rocking platform. The labeling reactions were terminated and the biotinylated cells were washed and collected by scraping in Tris-buffered saline (TBS) $(1 \times)$, followed by centrifugation at $500 \times g$ for $3 \mathrm{~min}$. The supernatants were discarded and the cell pellets were disrupted in manufacturer-provided lysis buffer by ultra-sonication using five 1-s bursts with a Sonifier 450 (Branson Sonifier, Wilmington, NC, USA). The cell lysates were centrifuged at $10,000 \times g$ for $2 \mathrm{~min}$ at $4^{\circ} \mathrm{C}$. Solubilized biotinylated cell-surface proteins in the clarified supernatants were isolated using NeutrAvidin Agarose. 
Cell-surface-bound proteins were eluted using $50 \mathrm{mM}$ DTT and precipitated with acetone overnight at $-20^{\circ} \mathrm{C}$. The pellets were stored at $-80^{\circ} \mathrm{C}$ until analysis.

The microsome (total membrane) subcellular glycoproteomes were obtained by first removing serum-free media, thoroughly washing cells with PBS $(1 \times)$, and harvesting cells in $25 \mathrm{mM}$ Tris- $\mathrm{HCl} \mathrm{pH}$ 7.4, $150 \mathrm{mM} \mathrm{NaCl}, 1 \mathrm{mM}$ EDTA containing a protease inhibitor cocktail (Roche Diagnostics). The cells were ultrasonicated on ice for three rounds of 10-s bursts using a Sonifier 450 and centrifuged at $2,000 \times g$ for $20 \mathrm{~min}$ at $4^{\circ} \mathrm{C}$ to remove intact cells and nuclei. The supernatants were ultra-centrifuged at $120,000 \times g$ for $80 \mathrm{~min}$ after which the supernatants were discarded. The microsomal membrane pellets were washed twice with ice-cold 0.1 M sodium carbonate and resuspended in $25 \mathrm{mM}$ Tris$\mathrm{HCl} \mathrm{pH} 7.4,150 \mathrm{mM} \mathrm{NaCl}$, and 1\% (v/v) Triton X-114. Samples were phase partitioned by incubation at $37^{\circ} \mathrm{C}$ for $20 \mathrm{~min}$, followed by $1,000 \times g$ centrifugation for $10 \mathrm{~min}$. The upper aqueous layer was carefully removed and nine volumes of ice-cold acetone were added to the lower detergent phase and incubated overnight at $-20^{\circ} \mathrm{C}$ to precipitate the proteins. The pellets were stored at $-80^{\circ} \mathrm{C}$ until further analysis.

The protein concentrations of the subcellular fractions were measured using Bradford reagents (Sigma). Equal protein amounts were precipitated in the three subcellular fractions and the resulting pellets were solubilized in $8 \mathrm{M}$ urea for spotting on PVDF membranes for $N$-glycome profiling or in NuPAGE LDS sample buffer for gel electrophoresis prior to proteome profiling.

\section{SUBCELLULAR FRACTIONATION OF HUMAN COLON CANCER CELL LINES}

SW480 cells $\left(5 \times 10^{7}\right)$ were washed twice with homogenization buffer ( $20 \mathrm{mM}$ HEPES, pH 7.5, and $0.25 \mathrm{M}$ sucrose). Cell pellets were resuspended to a final volume of $2 \mathrm{~mL}$ in homogenization buffer and lysed using an Ultra-Turrax disperser (Ika). After a low speed centrifugation at $1,000 \times g$ for $10 \mathrm{~min}$, the supernatant was collected as the post-nuclear fraction (PNF). The PNF was subjected to ultracentrifugation at $30,000 \mathrm{rpm}$ for $1 \mathrm{~h}$ in a SW41Ti rotor (Beckman Coulter) to pellet the microsome. ER and Golgienriched membranes were prepared as described (33). Briefly, $1 \mathrm{~mL}$ of PNF (usually 2.5-3 mg protein) was adjusted to $1.4 \mathrm{M}$ sucrose by adding $2 \mathrm{~mL}$ of $2 \mathrm{M}$ sucrose. A discontinuous sucrose gradient was made by sequentially loading $1.5 \mathrm{~mL}$ of $1.6 \mathrm{M}$ sucrose, $3 \mathrm{~mL}$ PNF in $1.4 \mathrm{M}$ sucrose, $3 \mathrm{~mL}$ of $1.2 \mathrm{M}$ sucrose, and $3 \mathrm{~mL}$ of $0.8 \mathrm{M}$ sucrose. All sucrose solutions contained $20 \mathrm{mM}$ HEPES $\mathrm{pH}$ 7.5. Ultracentrifugation was conducted at 28,500 rpm for $2 \mathrm{~h}$ in a SW41Ti rotor. Enriched-Golgi membranes were harvested at the $0.8 \mathrm{M} / 1.2 \mathrm{M}$ interface. Enriched ER membranes were harvested from the 1.4 M layer. The collected ER and Golgi membranes were diluted by homogenization buffer to reduce concentration of sucrose and subsequently pelleted by ultracentrifugation at $30,000 \mathrm{rpm}$ for $1 \mathrm{~h}$ in a SW41Ti rotor. Pelleted ER- and Golgienriched membranes were resuspended in $8 \mathrm{M}$ urea and protein concentrations were determined by BCA assays (Pierce).

\section{RELEASE AND PREPARATION OF $\boldsymbol{N}$-GLYCANS FROM SUBCELLULAR GLYCOPROTEOMES}

$N$-glycans were released from $\sim 20 \mu \mathrm{g}$ secreted proteins, $50 \mu \mathrm{g}$ cell-surface proteins, and $50 \mu \mathrm{g}$ microsome membrane proteins as previously described (27). Briefly, protein mixtures were immobilized on methanol-activated PVDF membranes (Millipore) and allowed to dry overnight. Membrane-bound proteins were incubated with $2.5 \mathrm{U}$ PNGase $\mathrm{F}$ (Flavobacterium meningospeticum, Roche) for $16 \mathrm{~h}$ at $37^{\circ} \mathrm{C}$ to ensure complete release of $\mathrm{N}$-glycans. Released $\mathrm{N}$-glycans were incubated with $100 \mathrm{mM}$ ammonium acetate ( $\mathrm{pH}$ 5) for $1 \mathrm{~h}$ at $\mathrm{RT}$ and subsequently dried by vacuum centrifugation. Reduction of $N$-glycans was performed with $20 \mu \mathrm{L} 1 \mathrm{M}$ sodium borohydride (Sigma) in $50 \mathrm{mM}$ potassium hydroxide (Sigma) for $3 \mathrm{~h}$ at $50^{\circ} \mathrm{C}$. Reactions were quenched with $2 \mu \mathrm{L}$ glacial acetic acid. Dual desalting was performed in micro-SPE formats using strong cation exchange/ $\mathrm{C}_{18}$ and carbon columns (27). Desalted $N$-glycans were eluted from the carbon columns with $20 \mu \mathrm{L} 40 \%$ acetonitrile (ACN) containing $0.1 \%(\mathrm{v} / \mathrm{v})$ trifluoroacetic acid and dried by vacuum centrifugation (34). Samples were stored at $-80^{\circ} \mathrm{C}$ if not analyzed immediately.

\section{DIGESTION AND PREPARATION OF PEPTIDE MIXTURES FROM SUBCELLULAR GLYCOPROTEOMES}

The subcellular glycoproteomes of the breast cells ( $~ 50 \mu \mathrm{g}$ protein/fraction) i.e., secreted, cell surface, and microsomes and of colon cells ( $\sim 10 \mu \mathrm{g}$ protein/fraction) i.e., microsome and ER- and Golgi-enriched membrane fractions were reduced and alkylated and subsequently in-gel (breast cells) or in-solution (colon cells) digested. Prior to in-gel digestion, samples were loaded in $10 \mu \mathrm{L}$ NuPAGE LDS buffer and separated on $4-12 \%$ Bis-Tris PAGE gels (Invitrogen). Electrophoresis was performed at $200 \mathrm{~V}$ for $50 \mathrm{~min}$. After separation of proteins, gels were fixed in $40 \%(\mathrm{v} / \mathrm{v})$ ethanol and $10 \%(\mathrm{v} / \mathrm{v})$ acetic acid for at least $2 \mathrm{~h}$, stained overnight with Coomassie Blue G250 (Bio-Rad) and destained in ultra-pure water (Millipore). In-gel trypsin digestion of all samples was performed from eight equal sized gel fractions. Each fraction was sliced into $1 \mathrm{~mm}$ pieces and placed in a 96-well plate. The gel pieces were destained with $50 \%(\mathrm{v} / \mathrm{v}) \mathrm{ACN}$ in $50 \mathrm{mM}$ ammonium bicarbonate until clear, dehydrated in $100 \%$ (v/v) ACN, and dried. Sequencegrade porcine trypsin (Promega) (1:30 enzyme/substrate, w/w) was used to digest the proteins overnight at $37^{\circ} \mathrm{C}$. Tryptic peptide mixtures were then collected and two rounds of gel extractions of peptides were performed with $2 \%(\mathrm{v} / \mathrm{v})$ formic acid in $50 \%$ (v/v) ACN and $50 \mathrm{mM}$ ammonium bicarbonate. The extracts were combined, peptide mixtures dried by vacuum centrifugation, redissolved in $10 \mu \mathrm{L} 0.1 \%(\mathrm{v} / \mathrm{v})$ formic acid, and desalted as described below. For in-solution digestion, samples were diluted to $<1 \mathrm{M}$ urea (final concentration) and trypsinized (sequencegrade porcine trypsin, 1:40 enzyme/substrate, w/w) overnight at $37^{\circ} \mathrm{C}$. Following proteolysis, the peptide mixtures were acidified by adding formic acid to a final concentration of $0.1 \%(\mathrm{v} / \mathrm{v})$. Desalted of peptide mixtures were performed using self-packed $\mathrm{C}_{18} \mathrm{SPE}$ tips. Briefly, $\mathrm{C}_{18}$ tips were washed three-time with $20 \mu \mathrm{L} 100 \%$ ACN, three-times with $20 \mu \mathrm{L} \mathrm{50 \%} \mathrm{(v/v)} \mathrm{ACN} \mathrm{in} 0.1 \%$ formic acid, and equilibrated with $50 \mu \mathrm{L} 0.1 \%(\mathrm{v} / \mathrm{v})$ formic acid. After sample loading, tips were washed three-times with $20 \mu \mathrm{L} 0.1 \%$ formic acid. Peptides were eluted with $20 \mu \mathrm{L} 60 \%$ (v/v) ACN in $0.1 \%$ formic acid and $20 \mu \mathrm{L} 90 \%(\mathrm{v} / \mathrm{v}) \mathrm{ACN}$ in $0.1 \%$ formic acid and dried. The desalted fractions were dried and stored at $-80^{\circ} \mathrm{C}$ until LC-MS/MS. 


\section{LC-MS/MS-BASED $\boldsymbol{N}$-GLYCOMICS}

$N$-glycans alditols were separated using a porous graphitized carbon (PGC) LC column [5 $\mu \mathrm{m}$ (particle size) Hypercarb KAPPA, $100 \mathrm{~mm}$ (length) $\times 200 \mu \mathrm{m}$ (ID), $250 \AA$ (pore size), Thermo Scientific] using an Ultimate 3000 HPLC system (Dionex) connected directly to an ESI-MS/MS HCT Ultra ion trap (Bruker Daltonics). Separation was performed using a binary gradient solvent system made up of solvent $\mathrm{A}$ (aqueous $10 \mathrm{mM} \mathrm{NH}_{4} \mathrm{HCO}_{3}$ ) and solvent B (90\% ACN/10 mM ammonium bicarbonate). The flow rate was $2 \mu \mathrm{L} / \mathrm{min}$ and a total gradient of $100 \mathrm{~min}$ was programed as follows: $0-2.5 \%$ solvent $\mathrm{B}$ for $0-13 \mathrm{~min} ; 2.5-17.5 \%$ solvent $\mathrm{B}$ for $14-48 \mathrm{~min}$; $17.5-50 \%$ solvent B for $48-65 \mathrm{~min}$; $50-100 \%$ solvent $B$ for $65-75 \mathrm{~min}$; $100 \%$ solvent B for $75-80 \mathrm{~min}$; back to $0 \%$ solvent B for $80-85 \mathrm{~min}$, and $100 \%$ solvent A equilibration for $15 \mathrm{~min}$. Settings for the MS/MS were as follows: drying gas flow: $6 \mathrm{~L} / \mathrm{min}$; drying gas temperature: $300^{\circ} \mathrm{C}$; nebulizer gas: 12 p.s.i.; skimmer: $-40.0 \mathrm{~V}$; trap drive: $-99.1 \mathrm{~V}$; and capillary exit: $-166 \mathrm{~V}$. Smart fragmentation was used with start- and end-amplitude of 30 and $200 \%$, respectively. Ions were detected in ion charge control set at 100,000 ions/scan and with maximum accumulation time of $200 \mathrm{~ms}$. MS spectra were obtained in negative ion mode with three scan events: a full scan $(m / z 400-2,200)$ at a scan speed of $8,100 \mathrm{~m} / \mathrm{z} / \mathrm{s}$ and data-dependent MS/MS scans after CID fragmentation of the top two most intense precursor ions with an absolute intensity threshold of 30,000 and a relative intensity threshold of $5 \%$ relative to the base peak. Dynamic inclusion was inactivated to ensure MS/MS generation of closely eluting $N$-glycan isomers. Precursors were observed mainly in charge states $Z=-1$ and/or -2 . Mass accuracy calibration of the mass spectrometer was performed using a well-defined tune mix (Agilent) prior to acquisition. $N$-glycans released from bovine fetuin served as positive controls for the sample preparation and the LC-MS/MS performance. Differences between observed and theoretical precursor and fragment masses were generally $<0.2 \mathrm{Da}$. Three LCMS/MS technical replicates were performed for the subcellular fractions.

\section{LC-MS/MS-BASED PROTEOMICS}

Three LC-MS/MS technical replicates of the subcellular proteomes of the breast cells were analyzed using a Q-Exactive (Thermo Scientific). Peptide mixtures in $0.1 \%(\mathrm{v} / \mathrm{v})$ formic acid were loaded onto a $\mathrm{C}_{18}$ reversed phase column packed in-house [2.7 $\mu \mathrm{m}$ (particle size) HaloLink Resins, Promega, column dimensions: $100 \mathrm{~mm}$ (length) $\times 75 \mu \mathrm{m}$ (ID)]. Separation of peptides was performed over a $60 \mathrm{~min}$ gradient with the first $50 \mathrm{~min}$ of the linear gradient increasing from 0 to $50 \%$ in solvent B $[0.1 \%(\mathrm{v} / \mathrm{v})$ aqueous formic acid/100\% (v/v) ACN] and then to $85 \%$ solvent B for the next $2 \mathrm{~min}$ and maintained at $85 \%$ for $8 \mathrm{~min}$. The flow rate was constant at $300 \mathrm{~nL} / \mathrm{min}$. The Easy-nLC (Thermo Scientific) was connected directly to the nano-ESI source of the Q-Exactive. MS full scans were acquired with resolution of 35,000 in the positive ion mode over $\mathrm{m} / z$ 350-2,000 range and an automatic gain control (AGC) target value of $1 \times 10^{6}$. The top 10 most intense precursor ions were then isolated for MS/MS using higher energy collisional dissociation fragmentation at 17,500 resolution with the following settings: collision energy: $30 \%$; AGC target: $2 \times 10^{5}$; isolation window: $m / z$ 3.0; and dynamic exclusion enabled. Precursors with unassigned or $Z=+1$ charge states were ignored for MS/MS selection.

The subcellular proteomes of the colon cells were LC-MS/MS analyzed using a Triple TOF 5600 (ABSciex). Peptides were separated by a nanoLC system (Eksigent) on a $\mathrm{C}_{18}$ reversed phase column [ProteCol $100 \mathrm{~mm}$ (length) $\times 150 \mu \mathrm{m}$, (ID): $3 \mu \mathrm{m}$ (particle size), $300 \AA$ (pore size); SGE Analytical Science] with a $90 \mathrm{~min}$ gradient from 5 to $40 \%$ solvent B [ $90 \%(\mathrm{v} / \mathrm{v})$ ACN with $0.1 \%$ formic acid] at a constant flow rate of $600 \mathrm{~nL} / \mathrm{min}$. The top 10 most intense precursor ions with $Z=+2,+3$, and +4 were selected for MS/MS using CID fragmentation.

\section{ANALYSIS OF $\boldsymbol{N}$-GLYCOME LC-MS/MS DATA}

$N$-glycome raw data for all subcellular glycoproteomes were viewed and manually analyzed using DataAnalysis v4.0 (Bruker Daltonics). Monoisotopic masses were obtained and searched against GlycoMod ${ }^{1}$ to obtain possible monosaccharide compositions, which were subsequently verified manually by de novo sequencing of corresponding MS/MS spectra and by taking account of PGC chromatographic retention time. The glycan type and the terminating monosaccharide determinants could unambiguously be identified using this method (27). The relative abundances of the observed $N$-glycans were determined using the ratio of the extracted ion chromatogram (EIC) peak area of each $N$-glycan species over the sum of EIC peak areas of all observed $N$-glycans in the sample. This has been shown to be a reasonably accurate method for relative $N$-glycan quantitation (35). The extent of $N$-glycan processing was measured by evaluating the relative molar proportion of the relative unprocessed species (i.e., immature mono-glucosylated glycans and high-mannose type $N$-glycans) and the processed species (i.e., hybrid, complex, and paucimannose type $N$-glycans) of the total $N$-glycome. In addition, the degree of monosaccharide determinants including $\alpha 1,2 / 3 / 6$-mannose, $\beta 1,3 / 4$-galactose, $\alpha 1,3 / 4 / 6$-fucose, and $\alpha 2,3 / 6$ sialic acid terminating $N$-glycans were calculated as a relative molar abundance of both the entire $N$-glycome and of the potentially modified $N$-glycan substrates (e.g., complex/hybrid-types). Since multiple determinants may be displayed by a given $N$-glycan, the total summed to more than $100 \%$.

\section{ANALYSIS OF LC-MS/MS-BASED PROTEOMIC DATA AND GENE ONTOLOGY}

For breast cell proteomes, raw spectra were converted to .mgf files using Proteome Discoverer Daemon v1.3 (Thermo Scientific) and searched against SwissProt protein database (Homo sapiens, 20,279 reviewed entries, November 2013 release) using the Global Proteome Machine (Cyclone). The following search criteria were used: carbamidomethylation was a fixed modification and oxidation and deamidation were variable modifications for methionine and asparagine/glutamine residues, respectively. Mass tolerances of $10 \mathrm{ppm}$ and $0.02 \mathrm{Da}$ were selected for precursor and product ions, respectively, with a maximum of two missed tryptic cleavages.

For colon cell proteomes, MS/MS spectra were extracted by ProteinPilot v4.2 (ABSciex) and searched using Mascot v2.4.0

${ }^{1}$ http://web.expasy.org/glycomod/ 
(Matrix Science) against SwissProt protein database (Homo sapiens, 20,253 entries, April 2013 release) using trypsin as the digestion enzyme. Precursor and product ion tolerances were $20 \mathrm{ppm}$ and $0.50 \mathrm{Da}$, respectively. Oxidation of methionine residues and carbamidomethylation of cysteine residues were used as variable modifications.

Scaffold v4.2.1 (Proteome Software) was used to validate MS/MS-based peptide and protein identifications. Peptides were accepted if they were confidently identified at $\geq 95.0 \%$ probability as evaluated by the local false discovery rate (FDR) algorithm. Proteins were included if they were confidently identified at $\geq 99.0 \%$ probability as assigned by the Protein Prophet algorithm incorporated in the software. Proteins containing shared or similar peptides, and which could not be differentiated based on MS/MS analysis alone, were grouped to satisfy the principles of parsimony. Proteins, which confidently shared identified peptides were grouped into clusters. Proteins were annotated using gene ontology (GO) terms from NCBI. The protein identifications were stringently filtered based on the presence of a minimum of two peptides in all replicates. The relative abundances of proteins were determined by conventional spectral counting and adjusted by taking the polypeptide length into account. Putative $N$-glycoproteins in the proteome of the subcellular fractions were predicted in sil$i$ co based on the presence of one or more sequons (NxT/S, $\neq \neq \mathrm{P}$ ) and a signal peptides (for secreted proteins) and/or transmembrane regions (for cell-surface and microsome proteins) using prediction tools including SignalIP (v4.1) (36), Transmembrane Hidden Markov Model (TMHMM v2.0) (37), PrediSi (38), and Phobius (39). Mitochondrial and nuclear membrane proteins were excluded as these are unlikely to enter the ER-Golgi glycosylation pathway. Ambiguous assignments were manually checked (validated or discarded) with information from Uniprot. Potential sequons were obtained using NetNGlyc (40). These in silico prediction tools generated lists of experimentally validated and putative glycoproteins. The 100 most abundant glycoproteins in each subcellular fraction were used to assess glycosylation site accessibility. The contribution of these glycoproteins to the total glycoproteome in each sample was estimated by multiplying the normalized spectral count of the individual glycoproteins with their potential glycosylation sites, a measure termed "sequon-weighted normalized spectral count."

\section{SELECTION OF PDB 3D STRUCTURE FOR GLYCOSYLATION SITE ACCESSIBILITY DETERMINATION}

Three-dimensional protein structures were obtained from the protein data bank (PDB) database ${ }^{2}$. If multiple structures were available for a glycoprotein, the best match to the naturally occurring variant was chosen by considering the following parameters in a prioritized order: (1) high protein sequence coverage and resolution of the 3D structure, (2) source of protein (purified from organism/tissue over artificial expression system), (3) known sitespecific mutations, (4) presence of artificial/natural ligands, and (5) oligomerization of the solved 3D structure. The experimentally obtained PDB structures used in this study were all based

\footnotetext{
${ }^{2} \mathrm{http}: / /$ www.rcsb.org/pdb
}

on X-ray crystallography, Table S2 in Supplementary Material. Where no experimentally determined structures were available (43\%), structure homologs were obtained from ProteinModelPortal $^{3}$, Swiss-model repository ${ }^{4}$, or ModBase ${ }^{5}$. High sequence homology was used as a selection criterion when choosing homology model. The average sequence homology for all structures was $67 \%$, which is considered very reliable for homology modeling (41), Table S1 in Supplementary Material. 3D protein structures were viewed with RasMol v2.7.5 (RasWin Molecular Graphics) for visual inspection.

\section{GLYCOSYLATION SITE ACCESSIBILITY DETERMINATION FROM MATURELY FOLDED GLYCOPROTEINS}

The glycosylation site solvent accessibility was determined by measuring the accessibility to the individual asparagine residues forming the glycosylation sites using NACCESS ${ }^{6}$ (42), an accurate and frequently used solvent accessibility determination program $(19,43-45)$. NACCESS calculates the atomic accessible area by predicting van der Waal's interactions when a probe is rolled around on the protein surface $(46,47)$. The maximum probe size offered by the program ( $5 \AA$ radius) was used as a default in this study to simulate as closely as possible the accessibility of the glycosylation enzymes to the glycosylation sites. NACCESS produces unit-less and absolute accessibility values as the output format (denoted "arb. units"), which are comparable between glycosylation sites of different glycoproteins (19). Prior to the measurements of site accessibility, any water molecules, sugars, ligands, and other hetero-atoms/molecules, not part of the core polypeptide chain, were removed from the protein surface. Negligible accessibility differences were observed for the "native" and the monomeric form of glycoproteins with quaternary structures (data not shown). Hence, in the case of multimers, glycosylation site solvent accessibilities derived from the monomeric structures were not considered in the analysis.

\section{STATISTICAL ANALYSIS}

All relative abundances of $N$-glycans were presented as a percentage out of $100 \%$ as mean \pm SD. Glycosylation site accessibilities were presented as mean \pm SEM to illustrate the potential spread of mean instead of the individual data points, which can be hugely influenced by the (local) accuracy and quality of the PDB structures. To overcome this potential issue of PDB "noise," relative large numbers of data points $(n)$ were needed. Data were analyzed using Prism v6 (GraphPad). One-way ANOVA analysis was performed for statistical comparison between the three subcellular fractions followed by post hoc Tukey's tests. All $p$ values were adjusted taking into account the multiple comparisons made and reported as multiplicity adjusted $p$ values. $p<0.05$ was regarded as statistically significant and indicated with "*." Stronger statistical significance was indicated as follows: ${ }^{* *} p<0.01 ;{ }^{* *} p<0.001 ;{ }^{* * *} p<0.0001$. Simple linear regression and corresponding correlation coefficients $\left(R^{2}\right)$ were obtained to evaluate the relationship between

\footnotetext{
${ }^{3} \mathrm{http}: / /$ www.proteinmodelportal.org

${ }^{4} \mathrm{http}: / /$ swissmodel.expasy.org

${ }^{5}$ http://modbase.compbio.ucsf.edu/modbase-cgi/index.cgi

${ }^{6}$ http://wolf.bms.umist.ac.uk/naccess/
} 
the degree of $N$-glycan processing in terms of glycan type and expression of terminal glycan determinants and the glycosylation site solvent accessibility.

\section{RESULTS \\ SUBCELLULAR-SPECIFIC $\boldsymbol{N}$-GLYCOSYLATION OF HUMAN BREAST EPITHELIAL CELLS}

Label-free quantitative $N$-glycome mapping of the secreted and microsome (total membrane) subcellular glycoproteomes of a panel of eight cultured human breast cells (i.e., MCF7, SKBR3, MDA157, MDA231, MDA468, HS578T, HMEC, and MCF10A) displaying diverse cellular features showed differential $N$-glycan processing of the two fractions, Figure 1A. The glycoproteins secreted into the cultured media consistently displayed a significantly higher proportion of processed $N$-glycan types (i.e., hybrid, complex, and paucimannose) (74.2-95.0\% $\mathrm{mol} / \mathrm{mol}$ of total $N$-glycome) than the high-mannose-rich microsomal subcellular glycoproteomes $(22.1-55.6 \%, p<0.0001-0.05)$. Little, if any, correlation between the $N$-glycan processing stage and the cellular doubling time $\left(R^{2}=0.13\right)$ or the protein secretion rate $\left(R^{2}=0.35\right)$, respectively, was detected of the secreted glycoproteomes across the cell line panel, Figure S1 in Supplementary Material. No correlation was detected between the $N$-glycan processing stage of the microsomal glycoproteins and the cellular doubling time $\left(R^{2}=0.04\right)$ or the protein secretion rate $\left(R^{2}=0.01\right)$.

In-depth, $N$-glycan profiling of the secreted, microsomal, and cell-surface enriched glycoproteomes was carried out for MCF7, MDA468, and MCF10A cells as representative cells for the breast cell line panel. Differential $N$-glycan processing was evident as exampled by the clear differences seen in the $N$-glycome $m / z$ profiles of the three subcellular fractions of MCF7 cells, Figure 1B. The cell-surface glycoproteins derived from MCF7 and MDA468 (but not MCF10A) cells were subjected to more $N$-glycan processing than microsomal proteins $(p<0.01-0.05)$ and all the three cell lines showed significantly increased abundance of the more processed $N$-glycans on the secreted proteins $(p<0.0001-0.01)$, Figure 1C.

\section{SUBCELLULAR-SPECIFIC DISTRIBUTION OF N-GLYCAN DETERMINANTS}

To further evaluate the subcellular-specific distribution of common $N$-glycosylation determinants, which may be recognized by different immuno-lectins, terminal $\alpha$-mannose, $\alpha$-fucose, and $\alpha$-sialic acid residues were mapped based on the obtained $N$ glycome profiles, Figure 1D. As expected from the glycan type distribution, terminating $\alpha$-mannosylation was found to be significantly reduced on the secreted and cell-surface proteins relative to the microsomal proteins. The $\alpha$-fucosylation, primarily of the $\alpha 1,6$-(core) type, and $\alpha 2,3 / 6$-sialylation were concomitantly significantly higher in the secreted fractions than in the cell-surface-enriched fraction (with the exception of fucosylation of MCF7) and in the microsomal fraction of all three cell lines. Taking the incomplete subcellular fractionation into account (see "Proteomics- and GO-Based Assessment of Subcellular Fractionation"), we estimate that very little terminal $\alpha$ mannosylation is present on protein $N$-glycans in contact with the extracellular environment in the investigated cells and that little $\alpha$-sialylation and $\alpha$-fucosylation are carried by intracellular (microsomal) $N$-glycoproteins.

\section{PROTEOMICS- AND GO-BASED ASSESSMENT OF SUBCELLULAR FRACTIONATION}

In total, 2,297, 2,636, and 2,042 human proteins were identified across the three subcellular fractions in MCF7, MDA468, and MCF10A, respectively. Putative $N$-glycoproteins fulfilling our strict prediction criteria i.e., presence of the following: one or more sequons $(\mathrm{NxT} / \mathrm{S}, \mathrm{x} \neq \mathrm{P}$ ); and signal peptides (for secreted proteins); and/or transmembrane regions (for membrane-tethered proteins) comprised significant proportions of the subcellular proteomes (15.7-31.0\%), Table S3A in Supplementary Material. The GO terms "ER", "Golgi/endosome/plasma membrane", and "extracellular" were used to evaluate the localization/origin of the glycoproteins identified in the subcellular fractions. In agreement with a previous study (23), the GO annotation of the identified proteins showed that the microsomes in general contained a high proportion of ER-residing proteins, Figures 2A-C. Although the proteins are only broadly, and possibly somewhat inaccurately, classified on the basis of GO terms, the trends clearly indicated significant enrichment, although not complete isolation, of the desired proteins in the respective subcellular fractions. The ER-based contribution to the microsome was supported by the fact that a significant proportion of the high-mannose $N$-glycans identified in this fraction were of the immature type i.e., $\mathrm{Man}_{9} \pm$ Glc $_{1}$ (MCF7: $35.3 \pm 0.9 \%$, MDA468: $40.2 \pm 2.0 \%$, and MCF10A: $31.8 \pm 0.4 \%$, $\mathrm{mol} / \mathrm{mol}$ of the total high-mannose $N$-glycans), Figure 2D (MCF7 data) and Figure S2 in Supplementary Material (MDA468 and MCF10A data).

To further investigate the intracellular $N$-glycosylation and confirm the presence of ER-rich microsomes, the $N$-glycome and proteome of ER- and Golgi-enriched fractions of human colon epithelial cancer cells (SW480) as prepared by the method of sucrose density gradient centrifugation, were mapped and compared to the microsome profiles derived from the same cells, Figure S3A in Supplementary Material. Quantitative analysis of four reliable and representative markers of the ER (i.e., $78 \mathrm{kDa}$ glucose-regulated protein, protein disulfide bond isomerase, calreticulin, and protein transport protein Sec61 alpha isoform 1) and Golgi (i.e., polypeptide $N$-acetylgalactosaminyltransferase 2, $\beta$-1,4-galactosyltransferase 1, Golgi apparatus protein 1, and Golgi membrane protein 1) compartments revealed a high abundance of ER-specific proteins in the ER-enriched fraction, Figure S3B in Supplementary Material. However, there was still a significant presence of ER proteins in the Golgi-enriched and microsome fractions. In contrast, the ER-enriched and microsome fractions were essentially free of Golgi proteins, Figure S3C in Supplementary Material. In line with our breast epithelial cell data, the proteins in the ER-enriched fraction contained a significantly higher degree of high-mannose $\left(\mathrm{Glc}_{0-1} \mathrm{Man}_{5-9} \mathrm{GlcNAc}_{2}\right)(92 \%) \mathrm{N}$-glycans than the proteins in the microsome (75\%) and the Golgi-enriched fraction $(51 \%)$. Taken together, the data confirm that the microsomes of human breast and colon epithelial cells predominantly contain ER proteins and that such intracellular proteins mostly carry highmannose type $N$-glycosylation. Since the Golgi fraction contains few, if any, ER proteins, it becomes clear that the majority of post-ER $N$-glycans are of the complex type. 


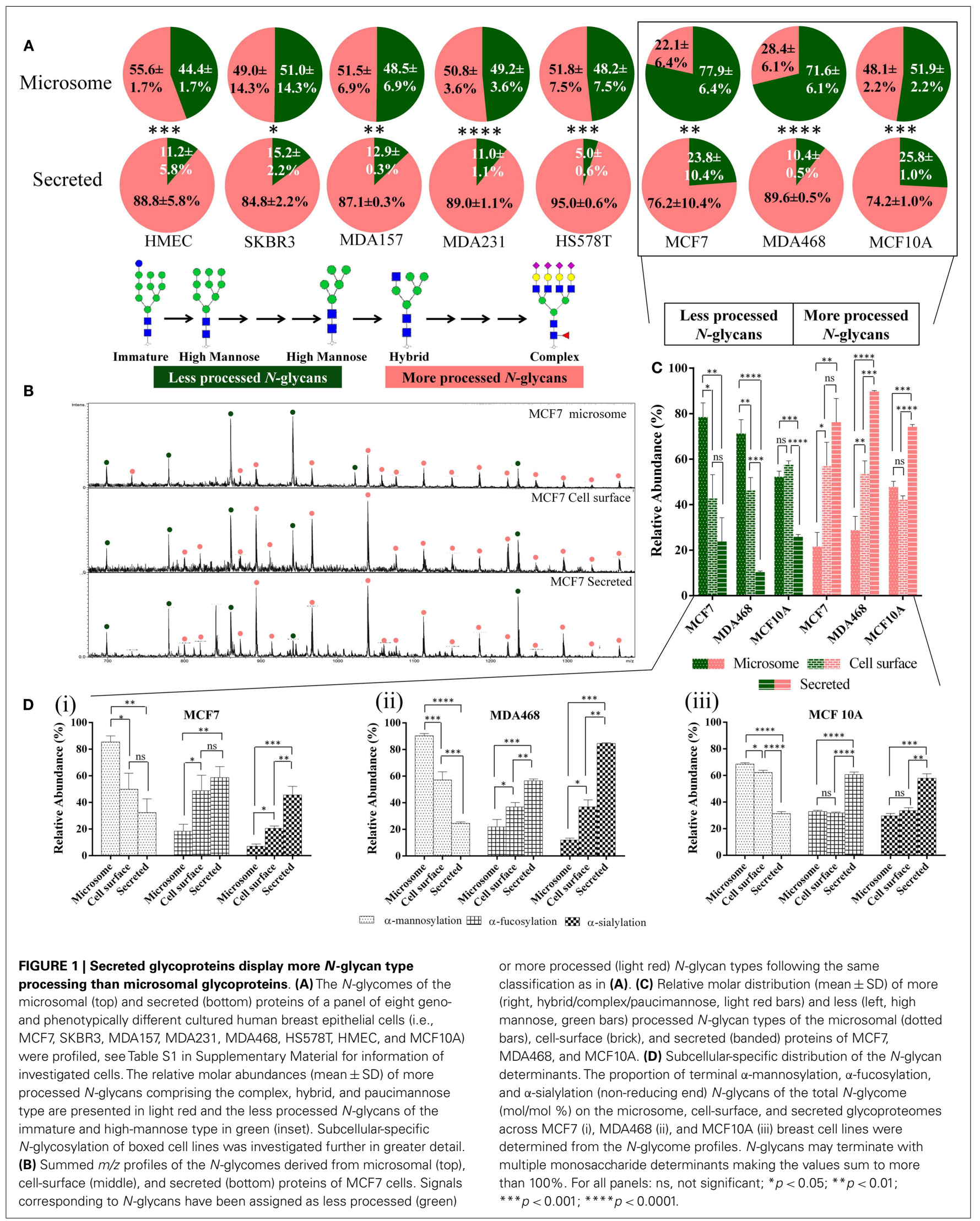




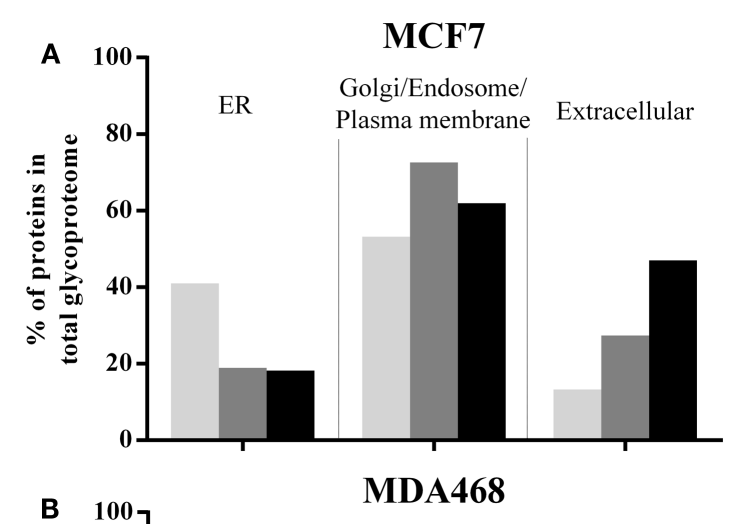
D Distribution of high mannose in subcellular fractions of MCF7
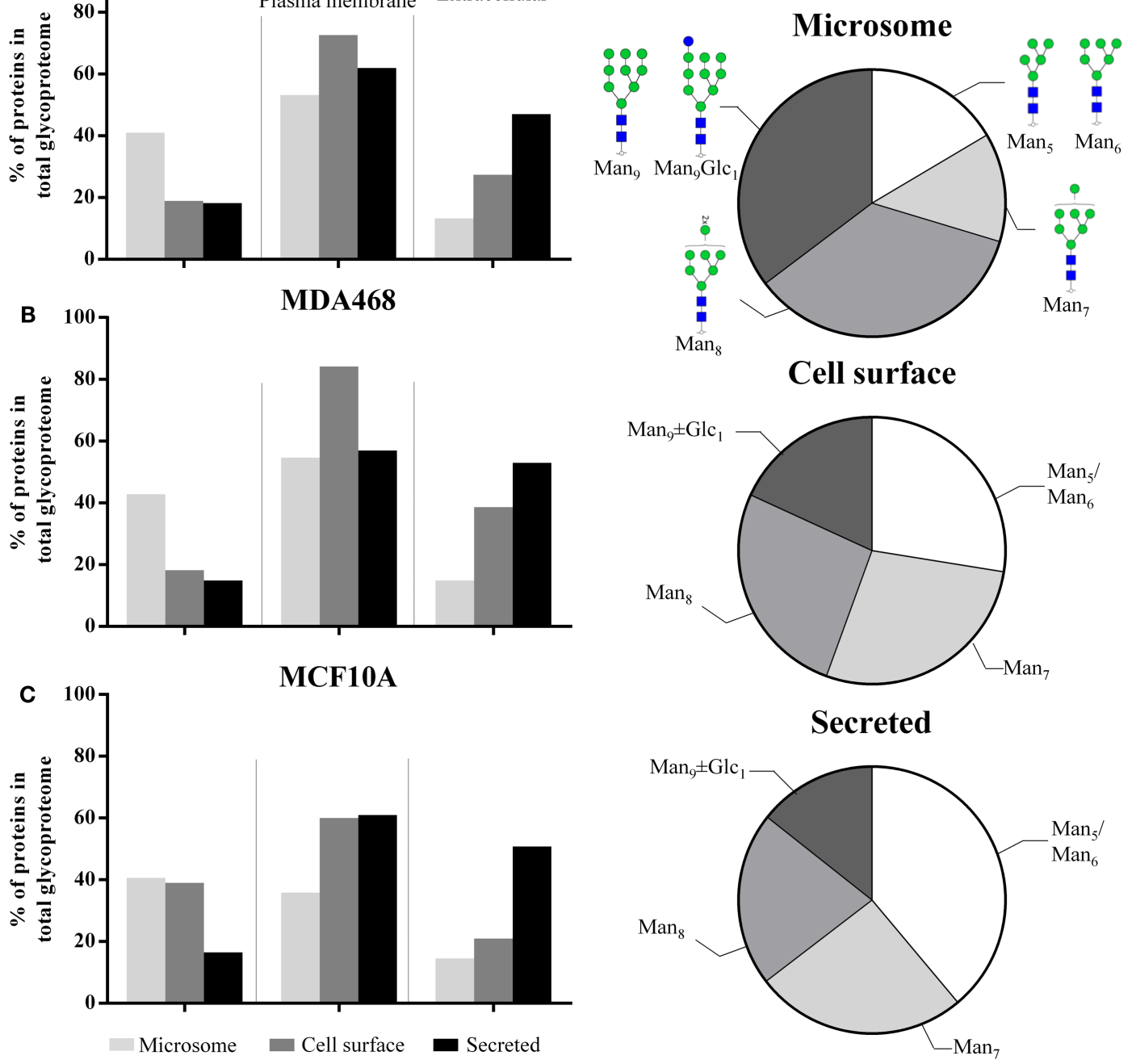

FIGURE 2 | (A-C) The subcellular proteomes of MCF7, MDA468, and MCF10A breast epithelial cell lines were mapped according to GO terms into ER, Golgi/endosome/plasma membrane, and extracellular region classifiers. This confirmed enrichment, but not isolation, of cell-surface and secreted proteins in the respective subcellular fractions. In addition, the classification confirmed that the microsomes contained a significant proportion of ER-residing

\section{DIFFERENTIAL Asn SITE ACCESSIBILITIES EXPLAIN SUBCELLULAR-SPECIFIC $\boldsymbol{N}$-GLYCOSYLATION}

To investigate a possible link between the observed subcellularspecific $N$-glycosylation and protein $N$-glycosylation site accessibility, in silico assessment of site accessibility was performed of the identified proteins predicted to be $N$-glycosylated. Due to the laborious and time-consuming approach of determining glycoprotein site accessibility (19), only the most abundant subset of the putative $N$-glycoproteins observed in the subcellular fractions were included in the accessibility assessment. The relative abundances of the individual putative glycoproteins were calculated by a conventional normalized spectral counting strategy; however, the number of sequons of the individual proteins was factored proteins. (D) The subcellular distribution of the high-mannose glycan type series on proteins derived from MCF7 into Man $, M^{2} \operatorname{Man}_{6}, \operatorname{Man}_{7}, \mathrm{Man}_{8}$, $\mathrm{Man}_{9} \pm \mathrm{Glc}_{1}$, the latter representing immature $N$-glycans normally only associated with intracellular ER N-glycosylation. See Figure S2 in Supplementary Material for the subcellular distribution of the high-mannose glycan type series of MDA468 and MCF10A. into the calculation to ensure a fair representation of heavily and lightly $N$-glycosylated proteins. We call this term "sequonweighted normalized spectral counts." Based on sequon-weighted normalized spectral counts, the 100 most abundant glycoproteins uniquely present in the three subcellular fractions, which, by weight, comprised $70-100 \%$ of the individual subcellular glycoproteomes, were used to assess glycosylation site accessibility, Table S3B in Supplementary Material. The solvent site accessibilities were determined using an established approach based on van der Waal interactions of the asparagine residue of the glycosylation sites to solvent (19). 3D-glycoprotein structures (experimental or homology modeled) were available for approximately onethird of the 189,89 , and 183 putative $N$-glycoproteins identified 


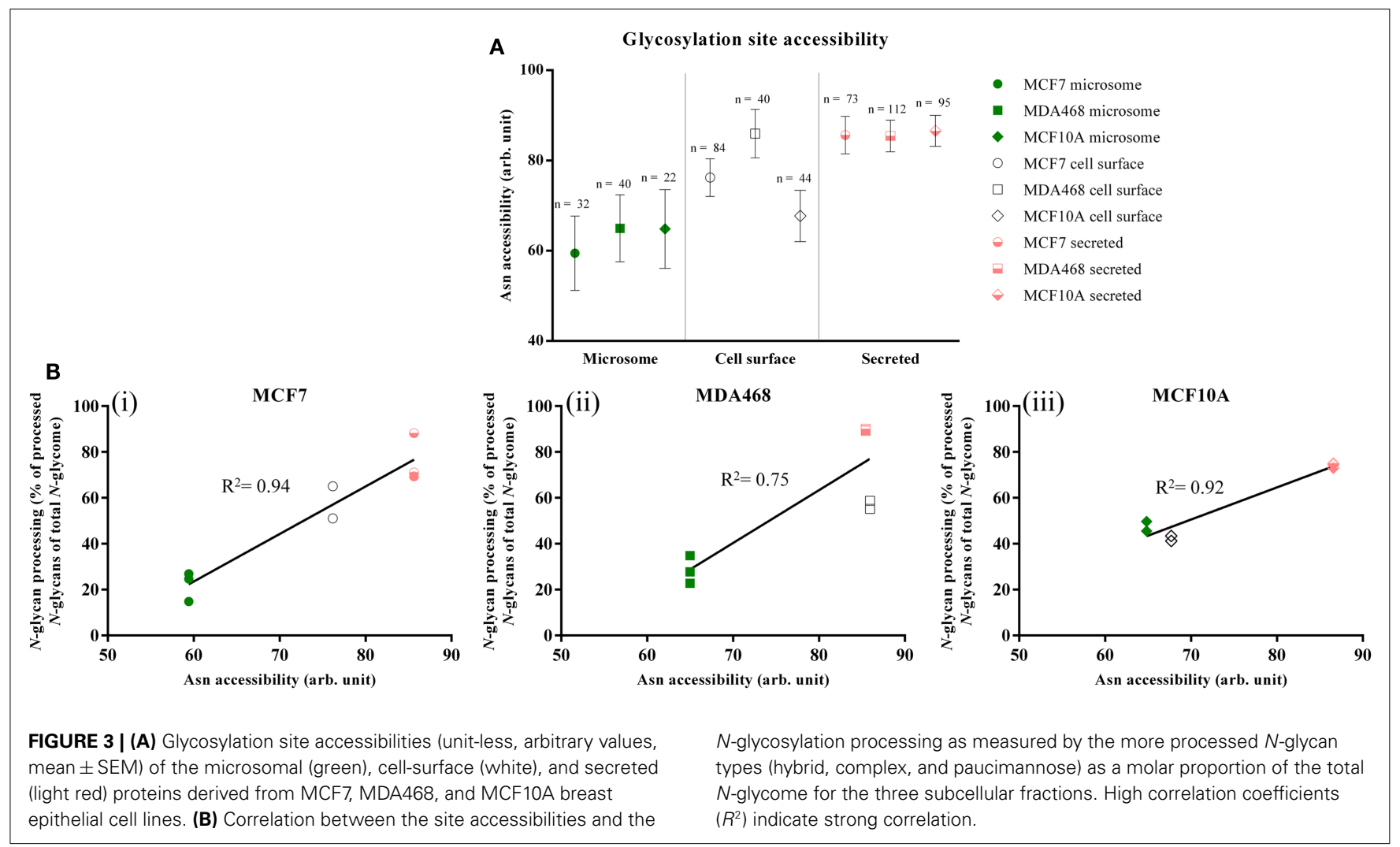

uniquely in the microsome, cell-surface, and secreted fraction, respectively, Figure S4 in Supplementary Material. This yielded site-accessibility datasets covering in total 161 (microsome), 189 (cell-surface), and 236 (secreted) $N$-glycosylation sites from the three cell types.

Differential site accessibilities were observed for the three subcellular glycoproteomes for all three investigated breast cell lines, Figure 3A (see also Figures S5A-C in Supplementary Material for an alternative representation showing 95\% confidence intervals). Glycosylation sites of secreted glycoproteins were significantly more accessible [MCF7: $85.63 \pm 35.47, n=73$; MD468: $85.44 \pm 36.85, n=112$; MCF10A: $86.56 \pm 33.54$ (all unit-less arbitrary values), $n=95$ ] than sites on microsomal proteins (MCF7: 59.44 $\pm 46.58, n=32$; MD468: $64.98 \pm 46.99, n=40$; MCF10A: $64.84 \pm 40.97, n=22, p<0.01)$. In agreement with the $N$-glycomes that carried a mixture of less processed highmannose and more processed $N$-glycan types, the sites of cellsurface proteins were intermediately accessible: cell-surface sites were either statistically similar in accessibility to the microsomal protein sites (MCF10A: $67.70 \pm 37.66, n=44$ ) or similar to the secreted protein sites (MCF7: 76.20 $\pm 38.13, n=84$; MD468: $85.95 \pm 34.08, n=40)$. For all three breast cell lines, the glycosylation site accessibilities were strongly correlated with the $N$-glycan processing as measured by their glycan type (MCF7: $R^{2}=0.94$; MD468: $R^{2}=0.75$; MCF10A: $R^{2}=0.92$ ), Figure 3B. Higher average glycosylation site accessibility of the secreted and partly also the cell-surface glycoproteins resulted, as such, in more $N$-glycan processing in terms of glycan type formation.
Other subcellular-specific $N$-glycosylation signatures including core fucosylation, $\beta$-galactosylation, and $\alpha$-sialylation were found to correlate only weakly or not at all with glycosylation site accessibility upon search for consistent trends across the three different cell lines, Table S4 in Supplementary Material.

\section{DISCUSSION}

\section{SUBCELLULAR-SPECIFIC PROTEIN $\boldsymbol{N}$-GLYCOSYLATION OF HUMAN CELLS}

All $N$-linked glycoproteins synthesized by a given cell are processed by a common glycosylation machinery. Despite this shared biosynthetic machinery, we observed that a panel of human breast epithelial cells of different geno- and phenotypes, reproducibly produced subcellular glycoproteomes with distinct $N$-glycosylation signatures. The $N$-glycans attached to proteins enriched from the cell-surface, and in particular the secreted glycoproteins, were significantly more processed with respect to their glycan type (i.e., hybrid/complex/paucimannose) than the predominantly highmannose type microsomal proteins for all investigated cells. As such, subcellular-specific $N$-glycosylation can be predicted to be a general cellular feature not restricted to the investigated breast epithelial cells. Deeper dissection of the intracellular organellespecificity of colon cell $\mathrm{N}$-glycosylation supported this concept. The capacity of human cells to generate multiple subcellular glycoproteomes displaying specific $N$-glycosylation profiles has, to the best of our knowledge, not been systematically investigated.

The importance of cell-surface $N$-glycosylation for cell-cell and cell-protein interactions has prompted several investigations 
of the cell-surface (alternatively termed plasma membrane) $N$-glycosylation. High-mannose type $N$-glycans, in particular $\mathrm{Man}_{8-9}$ structures, were previously reported to be the dominating features of the plasma membrane of human embryonic stem cells (48) and of cancer cells $(49,50)$. However, cell lysates and total membrane fractions similar to our microsome preparations were used in these studies suggesting significant contributions from intracellular high-mannose-rich ER-residing $N$ glycoproteins (23). Hence, the actual cell-surface $N$-glycomes in the previous work may not have been accurately captured. Specific cell-surface enrichment methods such as biotinylation labeling strategies used in this study or adhesion-based isolation methods (23) indicate that human cell-surfaces instead are generally decorated with more processed $N$-glycan types.

Of the six cancerous breast cells investigated in this study, only MCF7 and MDA468 displayed predominantly (>70\%) highmannose $N$-glycans of the microsomal proteins. Approximately equal distribution of high-mannose and the more processed $N$ glycan types of microsomal proteins were detected in the remaining four cancerous (SKBR3, MDA157, MDA231, and HS578T) and the two non-cancerous cells (HMEC and MCF10A). In addition, no consistent over-representation of high-mannose $N$-glycans were detected for the secreted proteins derived from the cancerous cell lines relative to the non-cancerous cell lines. Together this indicates that high-mannose $N$-glycosylation is not linked directly to tumorigenesis. Others have associated serum-derived highmannose $\mathrm{N}$-glycoproteins to pathogenesis including cancer and inflammation $(5,51)$; however, whether these under-processed species are a result of leakage of intracellular glycoproteins as a consequence of cell death or active cellular secretion from intact cells remains to be described. Based on in-depth comparative analysis of the $N$-glycomes derived from secreted proteins of breast and colon epithelial cells of non-cancerous and cancerous nature, we have recently identified several tumor- and sub-type specific $N$-glycosylation signatures amongst the complex $N$-glycans including alterations of sialylation, $\alpha 1,6$-fucosylation, and bisecting $\beta 1,4-$ GlcNAcylation (submitted) (52).

\section{SITE ACCESSIBILITIES MECHANISTICALLY EXPLAIN SUBCELLULAR-SPECIFIC $\boldsymbol{N}$-GLYCOSYLATION}

We have previously shown that solvent accessibility of the glycosylation site of $N$-glycoproteins is an important factor in generating protein- and site-specific $N$-glycosylation (19). We used literaturebased glycoprofiling of more than 100 mammalian glycoproteins produced under different cellular and physiological conditions to establish that site accessibility of maturely folded glycoproteins correlates with $N$-glycan processing features including glycan type, $\alpha 1,6$-fucosylation and $\beta 1,4 / 6-G l c N A c-b r a n c h i n g$. We emphasized in that study that relatively large datasets were required to compensate for the potential inaccuracy of the individual PDB structures and the relative simplistic solvent accessibility assessment simulating the accessibility of the processing glycosylation enzymes to the protein glycosylation sites.

Herein, we used a similar approach using our own $N$ glycosylation data acquired from eight cell lines fractionated into subcellular glycoproteomes to further explore the determining features of site-specific $N$-glycosylation in the context of subcellular localization of proteins. Homogenous cell cultures were an essential tool to ensure that the isolated subcellular glycoproteomes were produced simultaneously under the same physiological conditions of the glycosylation machinery. Although the $N$-glycomes, as expected, varied considerably between the different cell lines, our experimental data not only validated the strong correlation of the $N$-glycan type and the glycosylation site accessibility of maturely folded glycoproteins in agreement with our previously report (19), but also mechanistically explained that subcellularspecific $N$-glycosylation is driven by differences in site accessibilities of the individual glycoproteins ending up at different subcellular destinations, Figure 4. Intracellular (microsome) $\mathrm{N}$ glycoproteins receive little glycan processing of the high-mannose intermediates as a result of limited site accessibility, whereas the secreted $\mathrm{N}$-glycoproteins are modified almost entirely to more processed $N$-glycan types due to high site accessibilities. As such, $\mathrm{N}$-glycan processing may be a targeting signal or a requirement for intracellular (ER-Golgi-residing) glycoproteins to translocate to the surface for cell-surface integration/secretion via vesicles. Keeping in mind there may be many exceptions to the molecular trends presented here, it is tempting to view the glycosylation site accessibility, and, thus, the $N$-glycan type, as a crude predictor of subcellular location of human glycoproteins.

We have previously linked core fucosylation to glycosylation site accessibility (19). Interestingly, glycosylation site accessibility alone could not explain the differential core fucosylation of the subcellular fractionated proteins in our data: the secreted proteins did not have a higher degree of core fucosylation of complex/hybrid-type $N$-glycans than the cell-surface proteins although the secreted proteins had significantly higher accessibilities. This surprising observation may be explained by a possible advantage of the membrane-embedded cell-surface glycoproteins to achieve preferential interaction with the membranebound fucosyltransferase 8 (FUT8) facilitating the addition of $\alpha 1,6$-fucose residues to the chitobiose cores of $N$-glycans. Soluble (luminal) glycoproteins may be less likely to interact with FUT8. This explanation is congruent with our previous observation describing FUT8 discrimination of soluble $N$-glycoproteins over membrane $N$-glycoproteins (19). Similar processing preference was not observed for the multiple processing enzymes responsible for the formation of the glycan type. As expected, the glycan modification more distal from the protein surface i.e., $\beta$ 1,3/4-galactosylation and $\alpha 2,3 / 6$-sialylation were not found to be correlated with glycosylation site accessibility since the glycosyltransferases most likely have unhindered access to the substrates relatively far from the protein surface. By the same token, we cannot rule out that a more refined accessibility determination approach, which not only takes into account the glycosylation site solvent accessibility, but also the conjugated $N$-glycans (5356), may expose that other subcellular-specific $N$-glycan features correlate with site accessibility. New developments in glycoproteomics may also support and strengthen these observations by giving more accurate insight into the connectivity of glycosylation of the individual protein carriers (31). Finally, it should be emphasized that although the subcellular glycoproteomes share a common biosynthetic machinery, slightly different trafficking rates and/or routes to their final destinations are factors that may 


\section{Subcellular-specific $\boldsymbol{N}$-glycosylation}

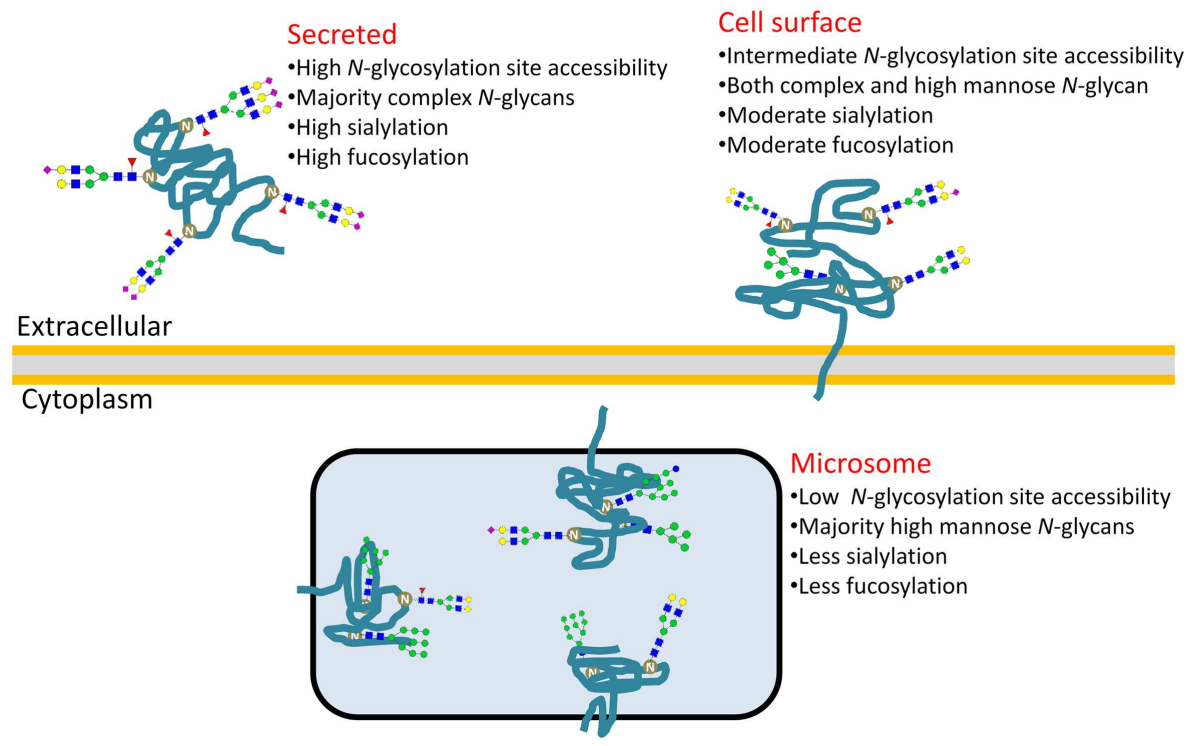

FIGURE 4 | Subcellular-specific $\boldsymbol{N}$-glycosylation is driven by differential solvent accessibility to the $\boldsymbol{N}$-glycosylation sites on maturely folded glycoproteins. Consequently, the $\mathrm{N}$-glycans of secreted, cell-surface, and microsomal proteins receive high, intermediate, and low $\mathrm{N}$-glycosylation processing, respectively, and as a result, display distinct glyco-determinant signatures. contribute to yield distinct subcellular $N$-glycosylation. Other cellular factors including the glycosylation enzyme activity or the availability of nucleotide donors may also indirectly contribute to subcellular-specific $N$-glycosylation by having differential effects on the individual subcellular glycoproteomes.

\section{SUBCELLULAR-SPECIFIC GLYCO-DETERMINANTS IN IMMUNITY}

The distinct $N$-glycosylation signatures carried by the subcellular glycoproteomes may be functionally important in immunity if we consider the key role of $N$-glycans as mediators for an effective innate and adaptive immune response through their specific interaction with endogenous lectins. In addition, opportunistic pathogens often use exposed $N$-glycan determinants as receptors for adhesion using exogenous lectins (11). The observed subcellular-specific glycosylation is here briefly discussed in the context of glyco-immunity and infection; it is stressed that further empirical evidence is required to validate these proposed relationships.

We found that $\alpha$-sialylation was a more abundant feature of the secreted $N$-glycoproteins than cell-surface proteins. High sialylation of secreted glycoproteins is essential to mask penultimate galactose residues from being exposed and recognized by asialoglycoprotein receptors, a C-type lectin (12). Thus, the high sialylation of secreted glycoproteins may be a requirement to ensure prolonged circulation half-life. In addition, high sialylation of secreted glycoproteins can act as a strong decoy for the less sialylated cellsurface proteins, to which opportunistic pathogens are known to adhere through sialic acid-recognizing I-type lectins (alternatively termed siglecs) $(57,58)$. Displaying less-than-complete sialylation of the cell-surface proteins also ensures that a gradient of biological activity toward endogenous siglecs for cellular signaling and endocytosis (59) is maintained through structural diversity, which may confer an immunological advantage to the host cells (60).

The secreted $N$-glycoproteins were over-represented in $\alpha 1,6$ core fucosylation relative to the cell-surface proteins. In line with our previous observations, the higher degree of core fucosylation may serve to either mask hydrophobic patches to regulate stability/solubility of the secreted $N$-glycoproteins (19) or to protect these more exposed proteins from proteolytic degradation in the extracellular environment. It could be speculated that the membrane-embedded nature of cell-surface glycoproteins would make them more stable by not facing solubility issues in their local environment and less vulnerable to proteolytic digestion, thereby having less requirement for steric protection provided by a bulky fucose residue proximal to the protein surface.

We and others have observed that $\alpha$-mannose is an unusual terminating structural determinant in the extracellular environment $(61,62)$. This may partly be explained by the intracellular functions of mannose (and glucose) terminating $N$-glycans $(16,17)$. The presence of several mannose recognizing lectins in the extracellular environment including mannan binding protein (MBP), DCSIGN, and macrophage mannose receptors may be relevant in the context of apoptosis when mannose terminating $N$-glycoproteins are exposed to the extracellular environment. In particular, MBP is a key player and a first line of defense in innate immunity, enabling phagocytosis of apoptotic cells through its binding to exposed immature or under-processed glycans or to pathogens carrying mannosylated glycoproteins $(63,64)$. Hiding mannose inside cells under physiological conditions could thus be viewed as being 
critical to avoiding the unnecessary onset of inflammation and auto-immunity. The presence of extracellular $\alpha$-mannosylation would, as such, be indicative of pathophysiological conditions. In support of this hypothesis, high-mannose containing glycoforms of intracellular adhesion molecule 1 and EGF receptor on cell-surfaces were shown to contribute to endothelial inflammation (61) and correlated with poor prognosis of various cancers, respectively $(61,62)$.

It has been noted that the structure and function of the protein $N$-glycome is different within and outside human cells and that these differences may be shaped by evolutionary forces (60). We are the first to systematically investigate and mechanistically explain some aspects of subcellular-specific $N$-glycosylation. We conclude that human cells have developed protein structure-specific mechanisms including differential $N$-glycosylation site accessibilities to generate subcellular glycoproteomes that display distinct $N$ glycosylation phenotypes using a shared biosynthetic machinery. Establishing this relationship is of general significance to glycobiologists and in particular to molecular immunologists due to the functional relevance of $N$-glycan determinants acting as ligands for the spectrum of endogenous lectins involved in facilitating an efficient immune response.

\section{ACKNOWLEDGMENTS}

This work was supported by Macquarie University Research Excellence Scheme postgraduate scholarship and ARC Super Science (FS110200026) and Discovery (DP110104958) Grants. Morten Thaysen-Andersen was funded an Early Career Fellowship by Cancer Institute NSW. The authors declare no conflict of interest.

\section{SUPPLEMENTARY MATERIAL}

The Supplementary Material for this article can be found online at http://journal.frontiersin.org/Journal/10.3389/fimmu. 2014.00404/abstract

\section{REFERENCES}

1. Freeze HH. Genetic defects in the human glycome. Nat Rev Genet (2006) 7(7):537-51. doi:10.1038/nrg1894

2. Freeze HH. Understanding human glycosylation disorders: biochemistry leads the charge. J Biol Chem (2013) 288(10):6936-45. doi:10.1074/jbc.R112.429274

3. Cylwik B, Naklicki M, Chrostek L, Gruszewska E. Congenital disorders of glycosylation. Part I. Defects of protein N-glycosylation. Acta Biochim Pol (2013) 60(2):151-61.

4. Venkatakrishnan V, Packer NH, Thaysen-Andersen M. Host mucin glycosylation plays a role in bacterial adhesion in lungs of individuals with cystic fibrosis. Expert Rev Respir Med (2013) 7(5):553-76. doi:10.1586/17476348.2013.837752

5. Scott DW, Patel RP. Endothelial heterogeneity and adhesion molecules $N$ glycosylation: implications in leukocyte trafficking in inflammation. Glycobiology (2013) 23(6):622-33. doi:10.1093/glycob/cwt014

6. Stuchlová Horynová M, Raška M, Clausen H, Novak J. Aberrant O-glycosylation and anti-glycan antibodies in an autoimmune disease IgA nephropathy and breast adenocarcinoma. Cell Mol Life Sci (2013) 70(5):829-39. doi:10.1007/ s00018-012-1082-6

7. Christiansen MN, Chik J, Lee L, Anugraham M, Abrahams JL, Packer NH. Cell surface protein glycosylation in cancer. Proteomics (2014) 14(4-5):525-46. doi:10.1002/pmic.201300387

8. Boscher C, Dennis JW, Nabi IR. Glycosylation, galectins and cellular signaling. Curr Opin Cell Biol (2011) 23(4):383-92. doi:10.1016/j.ceb.2011.05.001

9. Schwarz F, Aebi M. Mechanisms and principles of N-linked protein glycosylation. Curr Opin Struct Biol (2011) 21(5):576-82. doi:10.1016/j.sbi.2011.08.005
10. Helenius A, Aebi M. Roles of N-linked glycans in the endoplasmic reticulum. Annu Rev Biochem (2004) 73:1019-49. doi:10.1146/annurev.biochem.73. 011303.073752

11. van Kooyk Y, Rabinovich GA. Protein-glycan interactions in the control of innate and adaptive immune responses. Nat Immunol (2008) 9(6):593-601. doi:10.1038/ni.f.203

12. Figdor CG, van Kooyk Y, Adema GJ. C-type lectin receptors on dendritic cells and Langerhans cells. Nat Rev Immunol (2002) 2(2):77-84. doi:10.1038/nri723

13. Kawasaki T, Ii M, Kozutsumi Y, Yamashina I. Isolation and characterization of a receptor lectin specific for galactose $/ \mathrm{N}$-acetylgalactosamine from macrophages. Carbohydr Res (1986) 151:197-206. doi:10.1016/S0008-6215(00)90340-9

14. van Vliet SJ, Saeland E, van Kooyk Y. Sweet preferences of MGL: carbohydrate specificity and function. Trends Immunol (2008) 29(2):83-90. doi:10.1016/j.it. 2007.10.010

15. Rabinovich GA, van Kooyk Y, Cobb BA. Glycobiology of immune responses. Ann N Y Acad Sci (2012) 1253:1-15. doi:10.1111/j.1749-6632.2012.06492.x

16. Aebi M. N-linked protein glycosylation in the ER. Biochim Biophys Acta (2013) 1833(11):2430-7. doi:10.1016/j.bbamcr.2013.04.001

17. Aebi M, Bernasconi R, Clerc S, Molinari M. N-glycan structures: recognition and processing in the ER. Trends Biochem Sci (2010) 35(2):74-82. doi:10.1016/j.tibs.2009.10.001

18. Parodi AJ. Protein glucosylation and its role in protein folding. Annu Rev Biochem (2000) 69:69-93. doi:10.1146/annurev.biochem.69.1.69

19. Thaysen-Andersen M, Packer NH. Site-specific glycoproteomics confirms that protein structure dictates formation of $N$-glycan type, core fucosylation and branching. Glycobiology (2012) 22(11):1440-52. doi:10.1093/glycob/cws110

20. Sumer-Bayraktar Z, Nguyen-Khuong T, Jayo R, Chen DD, Ali S, Packer NH, et al. Micro- and macroheterogeneity of $N$-glycosylation yields size and charge isoforms of human sex hormone binding globulin circulating in serum. Proteomics (2012) 12(22):3315-27. doi:10.1002/pmic.201200354

21. Parekh RB, Dwek RA, Thomas JR, Opdenakker G, Rademacher TW, Wittwer AJ, et al. Cell-type-specific and site-specific $N$-glycosylation of type I and type II human tissue plasminogen activator. Biochemistry (1989) 28(19):7644-62. doi:10.1021/bi00445a021

22. Rudd PM, Dwek RA. Glycosylation: heterogeneity and the 3D structure of proteins. Crit Rev Biochem Mol Biol (1997) 32(1):1-100.

23. Mun JY, Lee KJ, Seo H, Sung MS, Cho YS, Lee SG, et al. Efficient adhesionbased plasma membrane isolation for cell surface $N$-glycan analysis. Anal Chem (2013) 85(15):7462-70. doi:10.1021/ac401431u

24. Bones J, Mittermayr S, O’Donoghue N, Guttman A, Rudd PM. Ultra performance liquid chromatographic profiling of serum $N$-glycans for fast and efficient identification of cancer associated alterations in glycosylation. Anal Chem (2010) 82(24):10208-15. doi:10.1021/ac102860w

25. North SJ, Hitchen PG, Haslam SM, Dell A. Mass spectrometry in the analysis of N-linked and O-linked glycans. Curr Opin Struct Biol (2009) 19(5):498-506. doi:10.1016/j.sbi.2009.05.005

26. Hua S, Lebrilla C, An HJ. Application of nano-LC-based glycomics towards biomarker discovery. Bioanalysis (2011) 3(22):2573-85. doi:10.4155/bio.11.263

27. Jensen PH, Karlsson NG, Kolarich D, Packer NH. Structural analysis of Nand O-glycans released from glycoproteins. Nat Protoc (2012) 7(7):1299-310. doi:10.1038/nprot.2012.063

28. Parker BL, Thaysen-Andersen M, Solis N, Scott NE, Larsen MR, Graham ME, et al. Site-specific glycan-peptide analysis for determination of $\mathrm{N}$ glycoproteome heterogeneity. J Proteome Res (2013) 12(12):5791-800. doi:10. $1021 /$ pr400783j

29. Nwosu CC, Seipert RR, Strum JS, Hua SS, An HJ, Zivkovic AM, et al. Simultaneous and extensive site-specific $\mathrm{N}$ - and O-glycosylation analysis in protein mixtures. J Proteome Res (2011) 10(5):2612-24. doi:10.1021/pr2001429

30. Zauner G, Koeleman CA, Deelder AM, Wuhrer M. Nano-HPLC-MS of glycopeptides obtained after nonspecific proteolysis. Methods Mol Biol (2013) 951:113-27. doi:10.1007/978-1-62703-146-2_9

31. Thaysen-Andersen M, Packer NH. Advances in LC-MS/MS-based glycoproteomics: getting closer to system-wide site-specific mapping of the $\mathrm{N}$ - and Oglycoproteomes. Biochim Biophys Acta (2014) 1844(9):1437-52. doi:10.1016/j. bbapap.2014.05.002

32. Kolarich D, Lepenies B, Seeberger PH. Glycomics, glycoproteomics and the immune system. Curr Opin Chem Biol (2012) 16(1-2):214-20. doi:10.1016/j. cbpa.2011.12.006 
33. Balch WE, Dunphy WG, Braell WA, Rothman JE. Reconstitution of the transport of protein between successive compartments of the Golgi measured by the coupled incorporation of N-acetylglucosamine. Cell (1984) 39(2 Pt 1):405-16. doi:10.1016/0092-8674(84)90019-9

34. Packer NH, Lawson MA, Jardine DR, Redmond JW. A general approach to desalting oligosaccharides released from glycoproteins. Glycoconj J (1998) 15(8):737-47. doi:10.1023/A:1006983125913

35. Leymarie N, Griffin PJ, Jonscher K, Kolarich D, Orlando R, McComb M, et al. Interlaboratory study on differential analysis of protein glycosylation by mass spectrometry: the ABRF glycoprotein research multi-institutional study 2012. Mol Cell Proteomics (2013) 12(10):2935-51. doi:10.1074/mcp.M113.030643

36. Petersen TN, Brunak S, von Heijne G, Nielsen H. SignalP 4.0: discriminating signal peptides from transmembrane regions. Nat Methods (2011) 8(10):785-6. doi:10.1038/nmeth.1701

37. Krogh A, Larsson B, von Heijne G, Sonnhammer EL. Predicting transmembrane protein topology with a hidden Markov model: application to complete genomes. J Mol Biol (2001) 305(3):567-80. doi:10.1006/jmbi.2000.4315

38. Hiller K, Grote A, Scheer M, Münch R, Jahn D. PrediSi: prediction of signal peptides and their cleavage positions. Nucleic Acids Res (2004) 32:W375-9. doi:10.1093/nar/gkh378

39. Kall L, Krogh A, Sonnhammer EL. A combined transmembrane topology and signal peptide prediction method. J Mol Biol (2004) 338(5):1027-36. doi:10.1016/j.jmb.2004.03.016

40. Gupta R, Brunak S. Prediction of glycosylation across the human proteome and the correlation to protein function. Pac Symp Biocomput (2002):310-22.

41. Chothia C, Lesk AM. The relation between the divergence of sequence and structure in proteins. EMBO J (1986) 5(4):823-6.

42. Hubbard SJ, Thornton JM. NACCESS Computer Program. Department of Biochemistry and Molecular Biology, University Colloge London (1993). Available from: http://wolf.bms.umist.ac.uk/naccess/

43. Engelen S, Trojan LA, Sacquin-Mora S, Lavery R, Carbone A. Joint evolutionary trees: a large-scale method to predict protein interfaces based on sequence sampling. PLoS Comput Biol (2009) 5(1):e1000267. doi:10.1371/journal.pcbi. 1000267

44. Tuncbag N, Gursoy A, Nussinov R, Keskin O. Predicting protein-protein interactions on a proteome scale by matching evolutionary and structural similarities at interfaces using PRISM. Nat Protoc (2011) 6(9):1341-54. doi:10.1038/nprot. 2011.367

45. Joseph AP, Valadié H, Srinivasan N, de Brevern AG. Local structural differences in homologous proteins: specificities in different SCOP classes. PLoS One (2012) 7(6):e38805. doi:10.1371/journal.pone.0038805

46. Chothia C. The nature of the accessible and buried surfaces in proteins. J Mol Biol (1976) 105(1):1-12. doi:10.1016/0022-2836(76)90191-1

47. Lee B, Richards FM. The interpretation of protein structures: estimation of static accessibility. J Mol Biol (1971) 55(3):379-400. doi:10.1016/0022-2836(71) 90324-X

48. An HJ, Gip P, Kim J, Wu S, Park KW, McVaugh CT, et al. Extensive determination of glycan heterogeneity reveals an unusual abundance of high mannose glycans in enriched plasma membranes of human embryonic stem cells. Mol Cell Proteomics (2012) 11(4):M111010660. doi:10.1074/mcp.M111.010660

49. Hua S, Saunders M, Dimapasoc LM, Jeong SH, Kim BJ, Kim S, et al. Differentiation of cancer cell origin and molecular subtype by plasma membrane $N$-glycan profiling. J Proteome Res (2013) 13(2):961-8. doi:10.1021/pr400987f

50. Liu X, Nie H, Zhang Y, Yao Y, Maitikabili A, Qu Y, et al. Cell surfacespecific $N$-glycan profiling in breast cancer. PLoS One (2013) 8(8):e72704. doi:10.1371/journal.pone.0072704

51. de Leoz ML, Young LJ, An HJ, Kronewitter SR, Kim J, Miyamoto S, et al. Highmannose glycans are elevated during breast cancer progression. Mol Cell Proteomics (2011) 10(1):M110.002717. doi:10.1074/mcp.M110.002717
52. Sethi MK, Thaysen-Andersen M, Smith JT, Baker MS, Packer NH, Hancock WS, et al. Comparative $N$-glycan profiling of colorectal cancer cell lines reveals unique bisecting GlcNAc and alpha-2,3-linked sialic acid determinants are associated with membrane proteins of the more metastatic/aggressive cell lines. $J$ Proteome Res (2014) 13(1):277-88. doi:10.1021/pr400861m

53. Frank M, Schloissnig S. Bioinformatics and molecular modeling in glycobiology. Cell Mol Life Sci (2010) 67(16):2749-72. doi:10.1007/s00018-010-0352-4

54. Lutteke T. Analysis and validation of carbohydrate three-dimensional structures. Acta Crystallogr D Biol Crystallogr (2009) 65(Pt 2):156-68. doi:10.1107/ S0907444909001905

55. Petrescu AJ, Milac AL, Petrescu SM, Dwek RA, Wormald MR. Statistical analysis of the protein environment of $N$-glycosylation sites: implications for occupancy, structure, and folding. Glycobiology (2004) 14(2):103-14. doi:10.1093/glycob/ cwh008

56. Petrescu AJ, Wormald MR, Dwek RA. Structural aspects of glycomes with a focus on N-glycosylation and glycoprotein folding. Curr Opin Struct Biol (2006) 16(5):600-7. doi:10.1016/j.sbi.2006.08.007

57. Sharon N. Carbohydrate - lectin interactions in infectious disease. In: Kahane I, Ofek I, editors. Toward Anti-Adhesion Therapy for Microbial Diseases. Springer (1996).p. 1-8. doi:10.1007/978-1-4613-0415-9_1

58. Peterson R, Cheah WY, Grinyer J, Packer N. Glycoconjugates in human milk: protecting infants from disease. Glycobiology (2013) 23(12):1425-38. doi:10.1093/glycob/cwt072

59. Crocker PR, Paulson JC, Varki A. Siglecs and their roles in the immune system. Nat Rev Immunol (2007) 7(4):255-66. doi:10.1038/nri2056

60. Varki A. Nothing in glycobiology makes sense, except in the light of evolution. Cell (2006) 126(5):841-5. doi:10.1016/j.cell.2006.08.022

61. Johns TG, Mellman I, Cartwright GA, Ritter G, Old LJ, Burgess AW, et al. The antitumor monoclonal antibody 806 recognizes a high-mannose form of the EGF receptor that reaches the cell surface when cells over-express the receptor. FASEB J (2005) 19(7):780-2. doi:10.1096/fi.04-1766fje

62. Scott DW, Dunn TS, Ballestas ME, Litovsky SH, Patel RP. Identification of a high-mannose ICAM-1 glycoform: effects of ICAM-1 hypoglycosylation on monocyte adhesion and outside in signaling. Am J Physiol Cell Physiol (2013) 305(2):C228-37. doi:10.1152/ajpcell.00116.2013

63. Ogden CA, deCathelineau A, Hoffmann PR, Bratton D, Ghebrehiwet B, Fadok VA, et al. C1q and mannose binding lectin engagement of cell surface calreticulin and CD91 initiates macropinocytosis and uptake of apoptotic cells. J Exp Med (2001) 194(6):781-95. doi:10.1084/jem.194.6.781

64. Takahashi K, Ezekowitz RA. The role of the mannose-binding lectin in innate immunity. Clin Infect Dis (2005) 41(Suppl 7):S440-4. doi:10.1086/431987

Conflict of Interest Statement: The authors declare that the research was conducted in the absence of any commercial or financial relationships that could be construed as a potential conflict of interest.

Received: 09 July 2014; accepted: 07 August 2014; published online: 25 August 2014. Citation: Lee LY, Lin C-H, Fanayan S, Packer NH and Thaysen-Andersen M (2014) Differential site accessibility mechanistically explains subcellular-specific $N$ glycosylation determinants. Front. Immunol. 5:404. doi: 10.3389/fimmu.2014.00404 This article was submitted to Immunotherapies and Vaccines, a section of the journal Frontiers in Immunology.

Copyright (c) 2014 Lee, Lin, Fanayan, Packer and Thaysen-Andersen. This is an openaccess article distributed under the terms of the Creative Commons Attribution License (CC BY). The use, distribution or reproduction in other forums is permitted, provided the original author(s) or licensor are credited and that the original publication in this journal is cited, in accordance with accepted academic practice. No use, distribution or reproduction is permitted which does not comply with these terms. 